\title{
EFFECT OF CENTRIFUGATION AND REPEATED WASHING ON THE FERTILIZING CAPACITY OF FOWL SPERMATOZOA
}

\author{
T.J.SEXTON \\ Animal Science Research Division, ARS, United States Department of Agriculture, \\ Beltsville, Md. 20705, U.S.A.
}

(Received 6th Fuly 1972)

The technique of washing has been used to study various biological processes of mammalian (Lardy \& Phillips, 1943; White, 1953a, b; Dott \& Walton, 1960; Brackett, 1969) and avian (Wilcox, 1958; Wilcox \& Clark, 1962) spermatozoa. In most of this work, the spermatozoa were diluted before washing. Emmens \& Swyer (1948) concluded that the effects of washing and dilution were analogous and therefore dilution of the semen before centrifugation might be expected to mask the effect of washing. The object of this study was to examine the effects of centrifugation and repeated washing on the fertilizing capacity of the spermatozoa of the fowl, Gallus domesticus, without prior dilution.

Pooled semen was collected from Athens random-bred roosters by abdominal massage (Burrows \& Quinn, 1935) and maintained at $41^{\circ} \mathrm{C}$ until insemination. Semen quality was assessed by estimating progressive motility (Bajpai \& Brown, 1963). In Exp. 1, the semen sample was divided into two equal fractions, one of which served as the uncentrifuged control. The other fraction was centrifuged at 404 or $552 \mathrm{~g}$ for $10 \mathrm{~min}$ and the spermatozoa were resuspended in the original seminal plasma according to the procedure described by White (1953b). A $0.05-\mathrm{ml}$ aliquot of this reconstituted semen and the control containing approximately $1.46 \times 10^{8}$ spermatozoa were then used for each insemination. All inseminations were carried out within 20 min of semen collection.

In Exp. 2, an aliquot of fresh semen was removed and maintained at $41^{\circ} \mathrm{C}$ to serve as the unwashed control. An aliquot of the remaining fraction was centrifuged one to three times at $404 \mathrm{~g}$ for $10 \mathrm{~min}$ each time. After each centrifugation, the supernatant was discarded and the spermatozoa were resuspended to the original volume with $0.155 \mathrm{~m}$-potassium phosphate buffer $(\mathrm{pH} 7 \cdot 2)$ and the sperm concentration was then estimated with a haemocytometer. After each washing, an aliquot was removed for insemination $(0.05 \mathrm{ml} / \mathrm{hen})$ and used within $10 \mathrm{~min}$.

In both experiments, the hens were inseminated weekly for 4 weeks. Eggs were collected daily for 1 week after insemination, stored at $15^{\circ} \mathrm{C}$, and incubated within 7 days. Fertility was determined by candling or breaking the eggs on Day 7 of incubation. The data were analysed by analysis of variance using a randomized complete-block design. Differences between treatment 
means were assessed by the Least Significant Difference Test (Steel \& Torrie, 1960). Percentages were transformed to $\arcsin \sqrt{ } \%$ before analysis.

Preliminary trials in this study indicated that $404 \mathrm{~g}$ was the minimum speed for adequate separation of spermatozoa and seminal plasma in undiluted fowl semen. Consequently, the centrifuge speeds used in this study with undiluted semen were higher than those which have been reported (300 to 395 g) for diluted mammalian semen (White, 1953a, b; Dott \& Walton, 1960; Brackett, 1969). As shown in Table 1, centrifugation at either 404 or $552 \mathrm{~g}$ had no significant effect on fertility. Centrifugation at $350 \mathrm{~g}$ has been found to have no influence on the motility or metabolism of diluted ram (White, 1953b; Dott \& Walton, 1960) and bull (Rothschild, 1959) spermatozoa.

Table 1. Effect of centrifugation on the fertilizing capacity of undiluted fowl semen

\begin{tabular}{c|cc}
\hline $\begin{array}{c}\text { Relative centrifugal } \\
\text { force }(\boldsymbol{g})\end{array}$ & \multicolumn{2}{|c}{ Fertility $(\%)$} \\
\hline 0 & $84 \cdot 88 \pm 3 \cdot 10^{*}$ & $85 \cdot 20 \pm 8 \cdot 12 \dagger$ \\
404 & $82 \cdot 47 \pm 5 \cdot 71$ & $-56.54 \pm 8 \cdot 54$ \\
552 & - & \\
\hline
\end{tabular}

The data represent a summary of two experiments.

* Mean and standard deviation of 229 eggs (range 211 to 248 ) representing thirty hens/treatment.

$\dagger$ Mean and standard deviation of 189 eggs (range 185 to 194 ) representing twenty hens/treatment.

Table 2. Effect of repeated washing on the sperm concentration and fertilizing capacity of fowl spermatozoa

\begin{tabular}{|c|c|c|}
\hline No. of washings & $\begin{array}{c}\text { Sperm concentration } \\
\left(10^{9} / m l\right) \dagger\end{array}$ & Fertility $(\%) \ddagger$ \\
\hline $\begin{array}{l}0 \\
1 \\
2 \\
3\end{array}$ & $\begin{array}{l}2.91 \pm 0.45 \\
2.20 * \pm 0.14 \\
2.09 * \pm 0.45 \\
2.29 * \pm 0.24\end{array}$ & 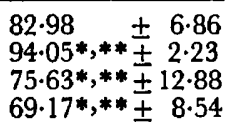 \\
\hline
\end{tabular}

$\dagger$ Mean and standard deviation for four determinations.

$\ddagger$ Mean and standard deviation of 116 eggs (range

84 to 141) representing ten hens/treatment.

* Significantly lower than unwashed $(P<0.05)$.

** Significantly different from each other $(P<0.05)$.

A single washing of spermatozoa resulted in a significant $(P<0 \cdot 05)$ improvement of fertility when compared to the unwashed control (Table 2). Wilcox (1958) reported a similar increase in fertility when spermatozoa of undiluted fowl semen were washed $(600 \mathrm{~g})$ with sodium phosphate buffer ( $\mathrm{pH} 7 \cdot 2)$. Removal of seminal plasma by washing may reduce natural contaminants such as urine and faeces, which are inimical to the survival of fowl spermatozoa in vitro (Lake, 1956). Chang, Hanada \& Hunt (1971) concluded that seminal 
plasma dose not seem to play an important rôle for the maintenance of the fertilizing capacity of rabbit spermatozoa.

Washing two or three times caused a reduction $(P<0.05)$ in fertility (Table 2$)$. The reduction in fertility is unlikely to be due to loss of spermatozoa during washing because (a) the cell count was not significantly reduced by repeated washing (Table 2) and (b) the total number of spermatozoa inseminated per hen $\left(104 \times 10^{6}\right)$ was well above the values $\left(80\right.$ to $\left.100 \times 10^{6}\right)$ reported for maximum fertility (Munro, 1938; Wilcox, 1958). The decrease in fertility might be partly explained by a loss of motility. Motility, which was estimated after each washing, was lower (less than $50 \%$ ) in the samples washed two and three times. White (1953b) reported that washing once had little influence on the motility of diluted $(1: 3)$ ram spermatozoa, but washing twice had an adverse effect. Another contributory factor may be provided by the leaching out or alteration of intracellular components which may accompany the washing procedure (White, 1953a; Dott \& Walton, 1960; Brackett, 1969). Hyaluronidase and other enzymes associated with fertilization have been known to pass readily from the sperm cell during washing (Mann, 1964).

The results of this study indicate that centrifuging undiluted fowl semen at 404 or $540 \mathrm{~g}$ has no effect on fertility. A single washing with phosphate buffer had a stimulatory effect on fertility, while repeated washing significantly reduced the fertilizing capacity of chicken spermatozoa. The reduction in fertility may partly be explained by a loss in motility rather than a reduction in the concentration of spermatozoa. In conclusion, the data from this study supports the recommendation of Mann (1945) that washing of spermatozoa should not be repeated more than once.

The author thanks Mrs T. A. Fewlass and Mr H. Attick for their technical assistance.

\section{REFERENCES}

BajpaI, P. K. \& Brown, K. I. (1963) The effect of some diluents on semen characteristics of turkeys. Poultry Sci. 42, 882.

BRACKeTt, B. G. (1969) Effects of washing the gametes on fertilization in vitro. Fert. Steril. 20, 127.

Burrows, W. H. \& Quins, J. P. (1935) A method of obtaining spermatozoa from the domestic fowl. Poultry Sci. 14, 251.

Ghang, M. C., Hanada, A. \& Hunt, D. M. (1971) Effects of seminal plasma on the fertilizing capacity of rabbit spermatozoa in relation to the time of ovulation. $\mathcal{F}$. Reprod. Fert. 27, 125.

DotT, H. M. \& WaLton, A. (1960) Effects of dilution and washing on ram spermatozoa studied by the flow dialysis technique 7. Reprod. Fert. 1, 350.

Emmens, G. W. \& SWYer, G. I. M. (1948) Observations on the motility of rabbit spermatozoa in dilute suspensions. F. gen. Physiol. 32, 121.

LAKE, P. E. (1956) A retarding factor in the problem of fowl semen storage. 3rd Int. Congr. Anim. Reprod. A.I., Cambridge, Sec. 3, 104.

LARdy, M. A. \& PHILlips, P. H. (1943) Effect of $\mathrm{pH}$ and certain electrolytes on the metabolism of ejaculated spermatozoa. Am. F. Physiol. 138, 741.

ManN, T. (1945) Studies on the metabolism of semen. Occurrence and distribution of cytochrome, certain enzymes and coenzymes. Biochem. 7. 39, 451.

Mann, T. (1964) The biochemistry of semen and of the male reproductive tract. John Wiley, New York.

Munro, S. S. (1938) The effect of dilution and density on the fertilizing capacity of fowl sperm suspensions. Can. F. Res. 16, 281.

Rothschind, L. (1959) Anaerobic heat production of bull spermatozoa. II. The effects of changes in the colligative and other properties of the surrounding medium. Proc. R. Soc. B, 151, 1. 
Steel, R. G. D. \& Torrie, J. H. (1960) Principles and procedures of statistics. McGraw-Hill, New York. Whrte, I. G. (1953a) Metabolic studies of washed and diluted ram and bull sperm. Aust. F. biol. Sci. 6,706 .

White, I. G. (1953b) The effect of washing on the motility and metabolism of ram, bull and rabbit spermatozoa. F. exp. Biol. 30, 200.

Wircox, F. H. (1958) The effect of dilution and concentration of chicken semen on fertility. Poultry Sci. $37,1357$.

Wilcox, F. H. \& Glark, R. G. (1962) Semen dilution during storage and washing. Poultry Sci. 41, 1091. 